\title{
Peer support services with integrated meaningful and challenging activity can be an effective early intervention for adolescent mental and social health issues
}

Version 3

\section{Introduction}

This article outlines a vision for the future through the development of peer communities within schools, lead by trained student peers which reduce social isolation and give young people the tools to self manage their own health.

Here we recognise that mental distress emerges from real world situations which evoke powerlessness, pressure, stress or fear. The routes to wellbeing will be rooted in real world activities, which return power to young people and promote self-regulation.

What does it mean to be well? Over the last 10 years wellbeing has become a topic of focus within schools and recently as part of the taught curriculum. The notion of wellbeing is reasonably vague as a psychological construct, while teachers are being increasingly asked to understand, teach and navigate their students towards positive wellbeing. Yet studies have found this approach to be ineffective ${ }^{40}$. Those students who remain distressed or anxious after these lessons may conclude that they simply have not understood what it is to be well22.

It should be recognised that wellbeing is not something which arises spontaneously from within but is a reflection of one's environment and perceived status within that environment. Wellbeing then, arises as a synergy between the self and one's power, autonomy and opportunity.

Where power is denied or abused, when freedoms are restricted, when ones' life becomes routine and numb with no opportunity to explore or grow - then this is experienced in the mind-body system as distress, and can be described in common language as: anxiety, depression, trauma, anger, violence and apathy.

The current paradigm in mental health is limited. In many cases, the origins of adverse mental health symptoms are thought to be located somewhere within the individual, rather than being recognised as a response to powerlessness or threat in the real world. 46 Wellbeing is often promoted as a drive for relentless positivity, a viewpoint which is simultaneously patronising and disempowering to those who feel unwell in the face of their lived reality. This viewpoint is also unrealistic - few people live their lives in a state of unbridled happiness. Furthermore, there is much research to indicate that happiness is not the same as wellbeing. Wellbeing speaks to deeper and longer lasting individual traits such as personal agency, access to skills, and access to power. Traits which serve to carry one across difficult waters as and when they arrive. 
If it is the case that wellbeing is a function of lived experience, then the health of individuals in a society must reflect the health of the society as a whole, and any solutions must take into account all systems involved: biological, social, educational and environmental.

Thinking more deeply around these systems can lead to the development of principles, processes and organisations with wellbeing at their heart, rather than just a part of the curriculum. Taking a big picture view of the situation in the UK is useful to understand the reason wellbeing is so high on the agenda.

\section{Adolescent mental health in the United Kingdom in 2019}

It is well recognised that there is an increasing number of young people in the UK presenting with mental health concerns. The British Medical Journal ${ }^{1}$ published an article last year with a summary of the current picture which describes a five-fold increase in young people presenting with mental health conditions (by the time they reach university) since 2007. Across the UK there has been a significant increase in metrics describing selfharm ${ }^{1}$, anxiety and depression, and suicide in young people ${ }^{3}$. In 2017 a review by the NHS described one in eight (12.8\%) 5 to 19 year olds as presenting with some kind of mental health concern².

The situation in the UK is being described in academic and clinical circles as a 'crisis'1. It should also be recognised by anyone concerned about public health that this is a crisis which in a few years will not just be bounded by adolescence. The current generation of young people will soon be adults. Unless steps are taken to identify causes and implement prevention strategies, the significant concerns of today are only likely to be amplified across society in the future. $75 \%$ of mental health issues persisting into adulthood are diagnosed before the age of 24 .

Our approach also considers behavioural health to be an extension of mental health. Levels of youth violence are increasing in urban areas in the UK, in particular knife crime and gang violence amongst young people. These behaviours often arise out of social and individual conditions which include poor mental health, and a lack of access to support.

\section{Causes}

Recognised risk factors such as abuse and trauma continue to remain relevant as drivers of poor mental health in young people (reported crime figures show that violent and sexual crimes have risen year on year since 20145), however it is important to look at the wider landscape in which young people today are being raised. Other studies point to family breakdown, violence in the home, material and social poverty, negative impacts from social media, and lack of opportunities are likely to be significant driving factors in poor behavioural and mental health8,9,10.

School environments have come under scrutiny in recent years. School is where most young people spend most of their time. Schools should be hubs for learning, development and growth, yet many schools are highly performance driven so that teachers have little time for innovation and creativity ${ }^{26}$. This is reflected in the current high turnover of teaching staff, with teaching staff reporting the primary reasons for poor job satisfaction being high workload to meet targets and inability to cope with poor student behaviour27. This 'poor 
behaviour' is having an impact on both teachers, and children: in the last 3 years school exclusions have risen $40 \% 28$.

The use of social media by young people has been flagged as a particular cause for concern. Highlighted no doubt due to its rapid and wide adoption amongst young people across the last 5 years, a time period which correlates with the described rise in poor mental health.

Metrics which equate to social validation, the inability to remove embarrassing or shaming posts and the ever present $24 \mathrm{hr}$ engagement, does not allow space for the mind to breathe. Recent research is starting to evidence a causal link - a comprehensive study in the Lancet this month showed that social media usage is correlated with increased depressive symptoms and low-self esteem in adolescent boys and girls ${ }^{7}$.

The role of nature is also useful to consider here. Young people today are increasingly disconnected from their natural environment. A research report developed over 3 years by the RSPB and University of Essex ${ }^{19}$, polled hundreds of young people and concluded near $80 \%$ of the children they spoke with felt disconnected from the natural environment ${ }^{20}$. The relationship between wellbeing and nature is becoming increasingly clear: spending more time in nature works wonders with attention, mood and anxiety $41,42,43$.

Modern life is changing behavioural patterns in adults and children. Increasingly urbanized environments, as well as a lack of outdoor play, leaves children spending more time indoors, overly dependent on screens for stimulation. The role that nature plays in good mental health is likely to be about more than simply being in natural environments (although this is the start), but also in giving opportunities for exploration and discovery. Programmes such as the Duke of Edinburgh award have long recognised this and sought to provide these opportunities for young people. Unsurprisingly, $97 \%$ of young volunteers said they feel happier after completing the program ${ }^{17}$.

\section{Statutory Services}

The current situation presents a challenge to mental health services. Increased awareness of mental health, and of the importance of early intervention means that young people today will be more likely to highlight challenges early - and that parents, teachers and GPs are likely to refer into CAMHS services in the first instance.

Across the country figures vary, but between $18 \%$ and $75 \%$ of young people who were referred into CAMHS were not able to access services due to increased demand 4 . In the South West, less than $10 \%$ of children and young people referred to CAMHS in 2015 received an immediate provision ${ }^{4}$. The systems and services designed to help young people navigate their mental health are overwhelmed with the scale of referrals. Thresholds are set so that only the most serious situations can be responded to with any urgency.

The volume of referrals that cannot be met with a response indicates that we now require approaches which speak to prevention, and not just seeking cures for the most severe situations. CAMHS ultimately remains a specialist service, out of reach of all but the most serious cases. 
The big picture of adolescent mental health seems complex, yet at the individual level the solutions could be straightforward. While there are no easy solutions to family breakdown or past trauma, there are ways to help give young people what they need to thrive in the world. The solutions proposed below are straightforward to implement, yet to be effective they need to be sustained over time, with committed authentic practitioners building relationships with young people and adjusted over time based on the needs of each individual.

Well established solutions seem to converge on a core set of principles:

1. Being part of a community: having a connection to other people which reduces isolation, and provides group norms to guide behaviour.

2. Engagement in a personal practice, often physical, which promote mastery and one's own skill development. Sustained physical practices promote self-regulation, a core driver of positive mental health.

3. A sense of service. Engagement in real and meaningful work that contributes to meaning in life.

4. Autonomy: having opportunity, adventure and the ability to go to the edge of what is known.

While these approaches may be novel in the current climate, they are not new. For millennia, humans have existed within communities, developed physical skills, contributed to the welfare of the whole, engaged in real work, and had the freedom to roam and explore. It is an unfortunate testament of our society that for so many young people, the routines and systems of their lives do not provide these basic and crucial methods. Individualised and atomised, the young person today risks being cut adrift in a society without vision or direction.

\section{Community}

Communities come in different forms, groups as diverse as a family, school class, faith group or urban gang can each be considered communities - which each differ in their behaviours, culture, customs and values. Of course, it is well known that young people without connection to any ongoing community may become isolated, leading to negative outcomes in social health and wellbeing. So primarily belonging is important, but it is just as important to consider the values and beliefs of the communities that young people subscribe to.

It is a normal part of adolescence to push back on the values of the dominant culture and and seek new identity, by inheriting the values, customs and behaviours of peer communities or new subculture. Anyone seeking to influence or work with young people must recognise the importance of community, both as a blessing and a curse.

Young people's services should both make space for - and be able to guide this process. Services can reduce the barriers to access, remove obvious hierarchy and create visual markers or tokens that create a shared identity. They can also give young people agency in decision making and a sense of ownership which reinforces participation in the group. The activities within the community should engage young people to push themselves further, innovate and play. Young people should be invited to remain part of this community over time and serve as inspiring leaders to new members.

\section{Service}


The concept of service refers to the ability to guide, help or contribute. Serving others develops self-esteem through skill development. Furthermore, serving others develops responsibility and purpose, enhancing meaning in life. Lewis (1996) states:

Service learning benefits students of all academic abilities... Teachers should use the principles of good service, make service a requirement, encourage service experiences based on real needs, design interdisciplinary service courses, consider opportunities for social change, provide mentorships, reduce liability, and help students track their progress 44 .

it is clear that young people are high in the potential to be of service, but how to activate these latent skills? Increasingly research has become focused on the benefits of play 48 . Play in this context means any opportunity for unstructured, self-led and self-directed activity. Educators can create this context by giving guidance around meaningful activities, but then allowing young people to self manage the process as much as possible.

Anyone who has spent time with young people in will recognise that, when inspired, young people highly desire to involve themselves in meaningful, productive tasks. A rounded school environment often makes space for this, however due to economic pressures it is more often than not independent schools that have the resources to allow for a broader, holistic curriculum - integrating indoor and outdoor education, creative pursuits and innovation. Creativity and innovation are the skills which are most needed for todays world. We no longer live in a world where skills in a single limited area can lead to a lifetime career. Young people today need a range of abilities across subjects and require the ability to know how to gather knowledge, work as part of a team and play across subject areas in order to be able to contribute to the modern world.

\section{Practice}

The importance of developing a personal practice has been neglected as a tool in developing mental resilience. The most effective practices improve self regulation, the process by which one self manages their own inner states (emotions, thoughts, beliefs). Posner and Rothbart argued that "understanding self-regulation is the single most crucial goal for advancing an understanding of development and psychopathology" 45

Physical practices which unite the breathing, mind and body (such as yoga, martial arts, gymnastics, capoeira, climbing amongst others) are highly effective at building self regulation, as well as self-esteem and skills. However, ultimately young people will have to choose those practices which suit their own interest and skills. Anything from coding, to learning a musical instrument; meditation or chess; activism to photography - all count as personal practices which give young people a sense of growth, power and ability.

\section{Adventure}

In traditional societies adolescence spells the entry into adulthood, and young people from as young as 12 or 13 go through some ritual process to mark this point. This ritual is facilitated by elders, and often involves a degree of significant challenge or risk, which gives the young adult opportunity to demonstrate skills, to overcome themselves, and grow and mature. Following the completion of the ritual, the young person enters adulthood and then accompanies adults in adult activities. Long arduous journeys, hunting and fighting, using weapons and tools, and taking responsibilities for younger members of the tribe - all become open to the young person once they make that transition. 
While we no longer live in a world of arduous journeys, hunting and fighting, there remains a deep seated need for challenge and risk when one reaches adolescence. If this is not provided in facilitated, directed paths, young people will seek their own rituals: drugs and alcohol, street level violence and weapons, risky sexual behaviour, self-harm. For many young people the structure of the academic school environment, followed by a home life marked by poverty of opportunities, is simply not meeting their emotional needs. A groundbreaking paper on understanding risk in adolescence states: "successful intervention [in mental health] depends on working with, instead of against, adolescent goals and motivations"49

From an adult perspective it is easy to reject this view as naive but consider that adults have endless opportunities to meet their own needs for challenge. Starting new relationships, moving into new areas of work and employment, buying expensive possessions like cars and houses, starting a family, pursuing and realising intellectual ambitions, extreme sports, travel. All of these are ways in which one meets that innate human need to go beyond the safe and sanitised. Few of these are open to young people today.

There is significant research to evidence the need for directed risk and challenge as part of adolescent life ${ }^{47}$. Exposure to this can provide significant benefits in individual and social health ${ }^{26}$. With this said, we should consider the example of a young person exposed to a stressful home life, or seeking escape from the impact of abuse or trauma. Are they also seeking challenge, adventure and risk? Probably not - more likely they are seeking peace, tranquility and calm.

Here we bring our focus back to the natural world. Outdoor environments provide, both the setting for challenge, risk and adventure, and simultaneously peace, tranquility and calm. While the type of activity may vary depending on the need of the individual (for example mountaineering vs food growing), reconnecting to nature is likely to be of benefit for both those needing challenge and those needing calm.

Diagram: Experiences of powerlessness, lack of safety, lack of opportunity lead to poor self regulation and protective threat responses leading to mental diststssttress and antisocial behaviour (black). Activities based on community, service, practice and adventure develop skills and ssttstrengths leaving young people empowered, with better ability to self regulate, leading to physical and mental health, and by extension a more healthy society (green)
LIVED EXPERIENCES

Powerlessness • Social/Emotional Threats • Lack of Opportunity

\section{PSYCHOLOGICAL RESPONSE}

Poor Self Regulation • Protective Threat Responses

\section{OUTCOMES}

Mental Distress • Antisocial Behavior

\section{INTERVENTION}

Community • Service • Practice • Adventure

PSYCHOLOGICAL RESPONSE

Skills • Strengths $\bullet$ Self Regulation $\bullet$ Power

OUTCOMES

Physical Health • Mental Health • Social Health 


\section{Adventure, Capitalism and Privilege}

It is also worth considering that access to nature, and access to adventure experiences, are in many cases off limits to those in minority demographics. Whether due to material poverty, social poverty, feeling unwelcome or having a disability, for many, exploring public lands may be a daunting prospect without additional support and guidance. For those who grew up with plenty of outdoor experiences, travelling to outdoor places is likely to be second nature. It is crucial for complete wellbeing that one is able to re-establish their connection with the land and can overcome the psychological and social barriers to accessing the gift of nature.

\section{Mental health for all, by involving all}

Over the last 8 years there has been a renewed interest in training non-professionals to perform tasks and deliver programs in community health11,12,13,14. Different terms - 'task shifting', 'peer support' or 'volunteer mentoring' - are used to describe this domain. The underlying premise is the same: make use of the innate helping skills within people, give them an avenue to develop those skills, and help their peers who need support and who, due to cost, wait times or other factors, cannot be supported by professional services.

Peer support and task shifting programs are well established in many settings, both in schools and in community health services in many countries. However in recent years they have received further attention from many large health bodies, including Public Health England (for the delivery of substance misuse interventions) ${ }^{15}$, The Department for Education $^{12}$ (for the delivery of adolescent mental health interventions) and the World Health Organisation ${ }^{16}$ (to deploy community midwives in Malawi and the UK).

This attention comes as part of the worldwide cultural shift in developing less hierarchical, more inclusive and more person-centered approaches in healthcare and psychology. Successful peer support services will empower and acknowledge the skills of individuals, and give participants in a context of shared experience and wellness. Peer networks have been shown to be highly effective in empowering young people to self-manage their own mental health and wellbeing both in the UK ${ }^{12}$ and internationally23,24.

There are a wide range of programs and definitions around peer support. We recognise the summary used in a Department for Education report:

"Using the knowledge, skills and experience of children and young people in a planned and structured way to understand, support, inform and help develop the skills, understanding, confidence and self-awareness of other children and young people with whom they have something in common". (Street and Herts, 2005) ${ }^{12}$

\section{Integrating peer support with meaningful activities}

Effective peer support services will benefit from the development of a supportive community based around helping others. This benefits both those helping and those being helped, yet this type of service is likely to be effective only for low-intensity mental health conditions. Burdening young people with the responsibility to hold and manage anything more serious is unlikely to be useful for those on either side of the conversation. 
Given this, integrating meaningful activities is more likely to give young people the skills they need to self-manage wellbeing and mental health. Furthermore this approach replaces the language of therapy with the language of success. The reinforcement of powerlessness is replaced with the reality of power.

\section{Beyond Peer Networks}

At the national scale, the complexity of adolescent mental health seems a daunting challenge to tackle. Yet other public health campaigns have been successful, even when applied to behaviours entrenched in society only a few years prior. In UK schools over the last 5 years there have been significant reductions in substance use (including alcohol, illegal drugs and smoking) ${ }^{32}$, homophobic bullying ${ }^{33}$, and impacts from poor sexual health ${ }^{34}$. Each of these reductions has followed changes to policy, and government or NGO strategy. This shows that public health interventions can be effective across populations over relatively short periods of time.

Just as many physical health issues can be resolved through bringing the body into balance, mental health issues resolve when the right environments are provided. And, just as the resolution of physical health issues requires sustained support over time, the same is true of mental health. Of course, the two domains of heath are intimately related. Physical, mental, community and social health are part of a single whole. The health of our society is defined by its symptoms. These symptoms are felt in the hearts and minds of those who are most vulnerable, and are measured in statistics around prison populations, school exclusions and suicide.

Straightforward solutions may take time to implement, especially when they fly in the face of many of the accepted wisdoms that pervade healthcare, education and environment. Recent headlines are starting to show cracks in the current paradigm: Yoga attenuates symptoms of schizophrenia35. Tae Kwon Do leads to better conduct in school36. Playing musical instruments and martial arts can manage tourettes symptoms ${ }^{37}$. Spending 5 minutes in nature improves mood ${ }^{38}$. Hearing voices or feeling paranoid is a common experience, and does not always need to be defined as an illness 39 .

These studies, and others like them, indicate that there are likely to be alternative approaches towards positive mental health which operate at the intersection of wellbeing services, education and environment. Further research and practice should aim to explore these areas in more depth, with the insight and experience of young people themselves.

Ashley Ward

ashley@native.org.uk

March 2019 


\section{References}

1. https://www.bmj.com/content/361/bmj.k2608

2. https://digital.nhs.uk/data-and-information/ publications/statistical/mental-health-of-childrenand-young-people-in-england/2017/2017

3. https://www.samaritans.org/sites/default/files/ suicide_statistics_report_final_dec_0.pdf

4. https://www.childrenscommissioner.gov.uk/wpcontent/uploads/2017/06/Childrens-CommissionersMental-Health-Lightning-Review.pdf

5. Although my statements on crime are based on Home Office figures, which in turn are based on crimes reported to police, it should be recognised that it is difficult to measure crime figures accurately. Police figures not representative of actual crime trends. Around a fifth of reported crimes are not recorded by police in the UK (including sexual assaults and rapes), furthermore some unknown proportion of crimes go unreported especially crimes which could affect young people: such as domestic violence, sexual offences, and non-homicide gang violence.

6. https://www.cps.org.uk/files/reports/original/ 111027123933-20100319PublicServicesAnEndToFa ctorySchools.pdf

7. https://www.thelancet.com/journals/eclinm/article/ PIIS2589-5370(18)30060-9/fulltext

Also from this paper: "School settings present opportunities for children and young people to learn how to navigate online life appropriately and safely and for interventions aimed at promoting selfesteem"

8. Albee, G. W. (2005) Call to revolution in the prevention of emotional disorders, Ethical Human Psychology and Psychiatry, 7(1) 37-44.

9. Albee, G. W. (2006) Historical overview of primary prevention of psychopathology: An invited address, The Journal of Primary Prevention, 27(5) 449-456.

10. Bradshaw, Jonathan (2007) Interview with the BBC and reported on website http://news.bbc.co.uk/1/hi/ uk/6359363.stm

11. https://www.ted.com/talks/ vikram_patel_mental_health_for_all_by_involving_all/ transcript

12. https://www.who.int/workforcealliance/knowledge/ themes/taskshifting/en/

13. https://assets.publishing.service.gov.uk/ government/uploads/system/uploads/ attachment_data/file/603107/ Children_and_young_people_s_mental_health_peer_ support.pdf
14. https://www.ncbi.nlm.nih.gov/pmc/articles/ PMC5719475/

15. https://assets.publishing.service.gov.uk/ government/uploads/system/uploads/ attachment_data/file/768979/

A_guide_to_communitycentred_approaches_for_health_and_wellbeing_full _report_.pdf

16. https://www.who.int/healthsystems/TTRTaskShifting.pdf

17. https://www.dofe.org/wp-content/uploads/2018/02/ Health-and-Wellbeing-Briefing.pdf

18. http://dx.doi.org/10.1080/13676261.2015.1112887

19. http://ww2.rspb.org.uk/Images/connecting-withnature_tcm9-354603.pdf

20. https://www.theguardian.com/environment/2013/ oct/16/uk-children-not-connected-nature-rspb

21. https://www.ncbi.nlm.nih.gov/pmc/articles/ PMC4695668/

22. http://www.centreforconfidence.co.uk/docs/ The_curiouscase.pdf

23. http://www.excellenceforchildandyouth.ca/sites/ default/files/resource/EIS_Youth_Peer_Support.pdf

24. https://www.nationalvoices.org.uk/sites/default/files/ public/publications/peer_support__what_is_it_and_does_it_work.pdf

The National Endowment for Science, Technology and the Arts reviewed peer support in order to answer the simple question - does peer support work?

A meta analysis of 524 studies found that peer support:

1. has the potential to improve experience, psychosocial outcomes, behavior, health outcome and service use among people with long term physical and mental health conditions is most effective for improving health outcomes when facilitated by trained peers

is most effective for improving health outcomes when delivered one to one or in groups of more than ten people

2. works well when delivered face-to-face, by telephone or online

3. is most effective for improving health outcomes when it is based around specific activities and focused on education, social support and physical support

4. works well in a range of venues

25. https://www.annualreviews.org/doi/full/10.1146/ annurev.publhealth.26.021304.144357? 
url_ver=Z39.88-2003\&rfr_id=ori\%3Arid\%3Acrossref. org\&rfr_dat=cr_pub\%3Dpubmed - see Challenge model of Resilience

26. https://www.cps.org.uk/files/reports/original/ 111027123933-20100319PublicServicesAnEndToFa ctorySchools.pdf

27. https://www.theguardian.com/education/2018/apr/ 10/lesson-battle-why-teachers-lining-up-leave

28. https://publications.parliament.uk/pa/cm201719/ cmselect/cmeduc/342/342.pdf

29. https://www.apa.org/pubs/journals/releases/ psp-101-1-164.pdf

30. Walker, J.S., Thorne, E.K., Powers, L.E., \& Gaonkar, R. (2010). Development of a scale to measure the empowerment of youth consumers of mental health services. Journal of Emotional and Behavioural Disorders, 18, 51-59.

31. Edwards, T. C., Huebner, C. E., Connell, F. A., \& Patrick, D. L. (2002). Adolescent quality of life, part I: Conceptual and measurement framework. Journal of Adolescence, 25(3),275-286.

32. https://youngminds.org.uk/media/1547/ymaddaction-briefing.pdf

33. https://www.stonewall.org.uk/sites/default/files/ teachers_report_2014.pdf

34. http://www.youngpeopleshealth.org.uk/wp-content/ uploads/2017/03/Young-Peoples-HealthUpdate-2017-final.pdf

35. https://www.ncbi.nlm.nih.gov/pmc/articles/ PMC3410202/

$+$ https://www.ncbi.nlm.nih.gov/pubmed/27187680

36. Lakes, K. D., \& Hoyt, W. T. (2004). Promoting selfregulation through school-based martial arts training. Journal of Applied Developmental Psychology, 25(3), 283-302.

37. https://scholarcommons.usf.edu/cgi/ viewcontent.cgi?referer=https://www.google.com/ \&httpsredir=1\&article=7383\&context=etd $+$ https://www.asiaone.com/asia/amir-khan-shareshow-martial-arts-helped-him-conquer-tourettesyndrome

38. https://www.tandfonline.com/doi/abs/ 10.1080/17439760.2018.1557242? journalCode=rpos20

39. https://www1.bps.org.uk/system/files/ Public\%20files/rep03_understanding_psychosis.pdf

40. https://jech.bmj.com/content/jech/58/12/997.full.pdf

41. https://academic.oup.com/bioscience/article/ $67 / 2 / 147 / 2900179$
42. http://agnesvandenberg.nl/adhd.pdf

43. Chown, A. (2014). Play therapy in the outdoors: Taking play therapy out of the playroom and into natural environments. Jessica Kingsley Publishers.

44. Lewis, B. A. (1996). Serving Others Hooks Gifted Students on Learning. Educational leadership, 53(5), 70-74.

45. Posner, M. I., \& Rothbart, M. K. (2000). Developing mechanisms of self-regulation. Development and Psychopathology, 12, 427 - 441

46. Smail, D. (2015). Illusion and reality: The meaning of anxiety. Karnac Books.

47. http://citeseerx.ist.psu.edu/viewdoc/download? doi=10.1.1.459.8678\&rep=rep1\&type $=p d f$

48. http://www.journalofplay.org/issues/3/4/article/ decline-play-and-rise-psychopathology-childrenand-adolescents

49. Ellis, B. J., Del Giudice, M., Dishion, T. J., Figueredo, A. J., Gray, P., Griskevicius, V., ... \& Wilson, D. S. (2012). The evolutionary basis of risky adolescent behavior: implications for science, policy, and practice. Developmental psychology, 48(3), 598. 